OPEN ACCESS

Edited by:

Michael Thomas-Poulsen

University of Copenhagen, Denmark

Reviewed by:

Anthony Yannarell,

University of Illinois at

Urbana-Champaign, USA

Christian Staehelin

Sun Yat-sen University, China

*Correspondence:

Xavier Perret

xavier.perret@unige.ch

Specialty section

This article was submitted to

Microbial Symbioses,

a section of the journal

Frontiers in Microbiology

Received: 18 July 2016

Accepted: 25 October 2016

Published: 11 November 2016

Citation:

Fossou RK, Ziegler D, Zézé A, Barja F and Perret $X$ (2016) Two Major Clades of Bradyrhizobia Dominate Symbiotic Interactions with Pigeonpea in Fields of Côte d'voire.

Front. Microbiol. 7:1793

doi: 10.3389/fmicb.2016.01793

\section{Two Major Clades of Bradyrhizobia Dominate Symbiotic Interactions with Pigeonpea in Fields of Côte d'Ivoire}

\author{
Romain K. Fossou ${ }^{1}$, Dominik Ziegler ${ }^{1,2}$, Adolphe Zézé ${ }^{3}$, François Barja ${ }^{1}$ and \\ Xavier Perret ${ }^{1 *}$ \\ ${ }^{1}$ Microbiology Unit, Department of Botany and Plant Biology, University of Geneva, Geneva, Switzerland, ${ }^{2}$ Mabritec AG, \\ Riehen, Switzerland, ${ }^{3}$ Laboratoire de Biotechnologies Végétale et Microbienne, Unité Mixte de Recherche et d'Innovation en \\ Sciences Agronomiques et Génie Rural, Institut National Polytechnique Félix Houphouët-Boigny (INPHB), Yamoussoukro, \\ Côte d'Ivoire
}

In smallholder farms of Côte d'Ivoire, particularly in the northeast of the country, Cajanus cajan (pigeonpea) has become an important crop because of its multiple beneficial facets. Pigeonpea seeds provide food to make ends meet, are sold on local markets, and aerial parts serve as forage for animals. Since it fixes atmospheric nitrogen in symbiosis with soil bacteria collectively known as rhizobia, $C$. cajan also improves soil fertility and reduces fallow time. Yet, seed yields remain low mostly because farmers cannot afford chemical fertilizers. To identify local rhizobial strains susceptible to be used as bio-inoculants to foster pigeonpea growth, root nodules were collected in six fields of three geographically distant regions of Côte d'Ivoire. Nodule bacteria were isolated and characterized using various molecular techniques including matrix-assisted laser desorption/ionization time of flight (MALDI-TOF) mass spectrometry (MS) and DNA sequencing. These molecular analyses showed that 63 out of 85 nodule isolates belonged to two major clades of bradyrhizobia, one of which is known as the Bradyrhizobium elkanii super clade. Phylogenies of housekeeping (16S-ITS-23S, rpoB) and symbiotic (nifH) genes were not always congruent suggesting that lateral transfer of nitrogen fixation genes also contributed to define the genome of these bradyrhizobial isolates. Interestingly, no field-, plant-, or cultivar-specific effect was found to shape the profiles of symbiotic strains. In addition, nodule isolates $\mathrm{Cl}-1 \mathrm{~B}, \mathrm{Cl}-36 \mathrm{E}$, and $\mathrm{Cl}-41 \mathrm{~A}$ that belong to distinct species, showed similar symbiotic efficiencies suggesting that any of these strains might serve as a proficient inoculant for C. cajan.

Keywords: nitrogen fixation, Cajanus cajan, nodulation, bio-inoculant, smallholders, MALDI-TOF MS

\section{INTRODUCTION}

Unlike cereals that must rely almost exclusively on chemical fertilizers to sustain their growth, legume crops can take advantage of nitrogen-fixing associations with soil bacteria that are collectively known as rhizobia. During these beneficial interactions, rhizobia exchange reduced forms of atmospheric nitrogen provided to host plants against all the macro- and micro-nutriments required to sustain symbiotic nitrogen fixation (Udvardi and Poole, 2013). Unlike free-living diazotrophs, many rhizobia must first establish persistent intracellular colonies inside plant cells 
of root nodules prior to the activation of functions required for nitrogen fixation (Masson-Boivin et al., 2009). During the nodulation process that allows rhizobia to infect nodule cells, host plants actively screen infecting bacteria for pathogens, or non-symbiotic strains via the exchange of multiple molecular signals (Perret et al., 2000; Oldroyd et al., 2011; Nelson and Sadowsky, 2015). In spite of such selectivity in the pairing of plant-bacteria symbionts, rhizobia belong to remarkably diverse microbial genera, possibly because lateral transfer of symbiotic genes contributes to diversify the number of rhizobial solutions to the legume needs (Masson-Boivin et al., 2009). In addition to conjugative symbiotic plasmids as in Sinorhizobium (Ensifer) fredii strain NGR234 (Freiberg et al., 1997), lateral transfer of genomic islands was shown to promote dispersal of symbiotic genes to various non-symbiotic recipient soil bacteria including mesorhizobia (Ramsay et al., 2006; Nandasena et al., 2007) and bradyrhizobia (Barcellos et al., 2007; Okubo et al., 2012). Such diversity of potential micro-symbionts in soils often reduces the beneficial effects of bio-inoculants on legume crops (Denton et al., 2002; Fening and Danso, 2002; Nandasena et al., 2007).

Amongst the many legumes that are cultivated worldwide, Cajanus cajan L. is primarily grown as a food crop by smallholder farmers of many tropical and subtropical regions (Varshney et al., 2010). Often cultivated as a sole crop or in mixed cropping systems with short-maturing cereals or legumes, $C$. cajan is valued for its protein-rich seeds that are used for human consumption and for its aerial parts that find application as forage and fodder (Varshney et al., 2010). In 2013, the annual production of $C$. cajan was estimated at $4.9 \times 10^{6}$ tons worldwide, of which $>60 \%$ was grown in India alone (FAO statistics; http:// faostat3.fao.org/browse/Q/QC/E). Being consumed as green peas or dry grains, C. cajan has become the main source of proteins for more than a billion people worldwide, and a cash crop that supports millions of resource-poor farmers in various developing countries (Mula and Saxena, 2010; Varshney et al., 2012). Traditionally grown as food to make ends meet in the northeast of Côte d'Ivoire, C. cajan is also cultivated for human consumption and animal feed in other parts of the country with distinct pedoclimatic characteristics (Ndabalishe, 1995). For example, in the political capital Yamoussoukro, pigeonpea seeds can be purchased on local markets and used as chicken feed (Fossou et al., 2012) while in the northern parts of the country late maturing varieties are favored as forage during the dry season (Charpentier et al., 1999). In addition, C. cajan was also tested as a plant to improve soil fertility in savannahs (Koné et al., 2012), to reduce the erosion of agricultural soils with 2-6\% slopes (Charpentier et al., 1999) and as an intercrop in upland rice cropping systems (Akanvou et al., 2002). In the context of the Heifer International Project, the ILRI 16555 cultivar of the International Livestock Research Institute (ILRI) in Ethiopia was introduced in 2004 in the center of Côte d'Ivoire as a perennial and vegetative legume for providing forage to cattle in cotton-based systems (Poussy Sébé, personnal communication). The ability of C. cajan to fertilize soils also justifies its use in smallholder farms of Asia and Africa where chemical fertilizers often are unaffordable. In such fields, C. cajan was measured to derive $65 \%$ of its nitrogen from biological nitrogen fixation (BNF)
(Herridge et al., 2008) and to release into soils a calculated 30-40 $\mathrm{kg} / \mathrm{ha}$ of nitrogen residues (Sheldrake and Narayanan, 1979).

Studies aiming at characterizing microbial symbionts of pigeonpea confirmed that, regardless the country in which the study was carried out, members of slow-growing bradyrhizobia species were favored over fast-growing bacteria. For examples, Bradyrhizobium elkanii was found to be the dominant symbiont in fields of Trinidad-Tobago (Ramsubhag et al., 2002) while several slow-growing rhizobial strains nodulating C. cajan in the Dominican Republic were reported to be closely related to Bradyrhizobium yuanmingense CCBAU $11071^{\mathrm{T}}$ (Araujo et al., 2015). Pigeonpea was also found to form efficient nodules with a number of fast-growing isolates including members of the Rhizobium (Wolde-Meskel et al., 2005; Degefu et al., 2013) or the Ensifer (formerly Sinorhizobium) genera (Stepkowski et al., 2003), amongst which strain NGR234 is well known for its exceptional broad host-range (Pueppke and Broughton, 1999). Yet, in spite of its importance in rural economies, little was known on root nodule bacteria (RNB) that form beneficial symbioses with pigeonpea in Côte d'Ivoire.

This work thus aimed at (i) establishing a catalog of rhizobia isolated from nodules of pigeonpea (Cajanus cajan L.) collected in Ivorian fields and at (ii) comparing the symbiotic efficiencies of representative nodule isolates. Until recently, reliable identification and characterisation of rhizobial isolates relied mostly on comparative analysis of marker genes. Often used as the primary phylogenetic marker, the $16 \mathrm{~S}$ ribosomal RNA (rRNA) gene was shown to provide robust bacterial phylogenies (Schleifer, 2009) but also to lack resolving power at and below species level (Willems, 2006) as well as to result in ambiguous assignments when bacteria harbored multiple and divergent copies of $16 \mathrm{~S}$ rDNA sequences (van Berkum et al., 2003). Multilocus sequence analysis (MLSA) of conserved protein-coding core genes was shown to overcome some of these limitations, and was successfully used to delineate species within rhizobial genera such as Ensifer (Martens et al., 2008), and Bradyrhizobium (Rivas et al., 2009) or to support the creation of the Neorhizobium genus (Mousavi et al., 2014). However, recent genome analyses confirmed that horizontal gene transfer and intergenic recombination often impaired taxonomic classification (Tian et al., 2012; Zhang et al., 2012). Given its potential to facilitate and expedite the exploration of rhizobial diversity in agricultural and natural ecosystems (Ziegler et al., 2012), matrix-assisted laser desorption/ionization time of flight (MALDI-TOF) mass spectrometry (MS) has become a rapid and reliable alternative to DNA sequencing for the identification of nodule isolates (Ferreira et al., 2011; Sánchez-Juanes et al., 2013) or their classification (Jia et al., 2015). In fact, MALDI-TOF MS was found to be so efficient in discriminating between closely related strains, that a large reference database covering all of the major rhizobial genera was established (Ziegler et al., 2015).

Here we report on the sampling of pigeonpea nodules in six fields of three distant regions of Côte d'Ivoire, and the subsequent isolation and molecular characterization of nodule bacteria. Once sorted into separate phyletic clusters based upon their MALDITOF MS signatures, a subset of strains representing the diversity of the 85 nodule isolates was characterized at the molecular level 
using MLSA of 16S rDNA, internal transcribed spacer (ITS), and $r p o B$ ( $\beta$-subunit of RNA polymerase) chromosomal marker genes. Symbiotic properties of representative nodule isolates were assessed by inoculating each strain separately onto a set of legume species that were grown in standard laboratory conditions, as well as by sequencing the respective nifH genes often used to study the evolution of nitrogen-fixing bacteria (Raymond et al., 2004).

\section{MATERIALS AND METHODS}

\section{Bacterial Growth Conditions}

Strains that were isolated during this study are listed in Table S1. Nodule isolates and the spontaneous rifampicinresistant derivative of reference Sinorhizobium (Ensifer) fredii strain NGR234 (Stanley et al., 1988) were grown at $27^{\circ} \mathrm{C}$ in/on tryptone-yeast (TY) (Beringer, 1974) or rhizobial minimal medium supplemented with $12 \mathrm{mM}$ succinate (RMS) as sole carbon source (Broughton et al., 1986).

\section{Isolation of Nodule Bacteria}

Fields and number of plants sampled in each of them are listed in Table 1. Once collected from roots, nodules were desiccated in plastic tubes containing silica gel and stored at $4^{\circ} \mathrm{C}$ until further analysis. Prior to isolation of nodule bacteria, plant tissues were incubated overnight at $4^{\circ} \mathrm{C}$ in sterile double distilled water $\left(\mathrm{ddH}_{2} \mathrm{O}\right)$. Once nodules were rehydrated, the remaining soil traces were carefully removed. Sterilization of nodule surface was carried out using one initial $3 \mathrm{~min}$ incubation in $70 \%(\mathrm{v} / \mathrm{v}) \mathrm{EtOH}$ followed by $3 \mathrm{~min}$ in $4 \%$ (w/v) sodium hypochlorite solution and thorough washing with sterile $\mathrm{ddH}_{2} \mathrm{O}$. Once sterilized, nodules were rolled onto TY agar plates (TYA) to check for remaining surface contaminants. Each nodule was then crushed into $50 \mu \mathrm{l}$ of sterile $\mathrm{ddH}_{2} \mathrm{O}$, and an aliquot of the nodule lysate was used to inoculate a Petri dish containing TYA. All plates were incubated at $27^{\circ} \mathrm{C}$ and bacterial growth monitored each day. When nodule isolates started growing, a sample was used to inoculate a liquid culture which, following subsequent serial dilutions was used to isolate single colonies on RMS. Thus, all of the isolates described in this study were purified from a single colony.

\section{Molecular Characterization of Nodule Isolates}

To obtain a preliminary identification and sorting of nodule isolates, each strain was cultivated separately on TYA and at $27^{\circ} \mathrm{C}$. When growth was sufficient, each isolate was analyzed in quadruplicate by mass spectrometry as described in Ziegler et al. (2015). Briefly, free-living bacteria were spotted onto MALDI steel target plates, overlaid with $1 \mu \mathrm{l}$ of $25 \%$ formic acid, air-dried, and again overlaid with $1 \mu$ l of matrix solution consisting of saturated alpha-cyano-4 hydroxycinnamic acid (CHCA; Sigma-Aldrich, Buchs, Switzerland) in 33\% acetonitrile (Sigma-Aldrich), 33\% ethanol and 3\% trifluoroacetic acid (TFA). Once dried, bacterial spots were analyzed with MALDI-TOF Mass Spectrometer Axima ${ }^{\mathrm{TM}}$ Confidence machine (ShimadzuBio- tech, Kyoto, Japan) using the linear positive detection mode, a laser frequency of $50 \mathrm{~Hz}$ and a mass range of $3-15 \mathrm{kDa}$. For each isolate, spectra consisting of 50-100 protein masses were averaged and processed using the Launch-pad ${ }^{\mathrm{TM}} 2.8$ software (Shimadzu-Biotech). For identification purposes, mass spectra were matched against the PARPM and the "rhizobia-specific module" of the SARAMIS ${ }^{\mathrm{TM}}$ databases that were described previously (Ziegler et al., 2015). When isolates did not match any of the reference rhizobial strains, the search was extended to bacteria included in a proprietary and enlarged version of the SARAMIS $^{\text {TM }}$ database (Mabritec AG). For hierarchical clustering of protein masses, a binary matrix listing presence/absence of masses was generated using the SARAMIS Superspectra tool (see Table S5). Results were then imported into the PAleontological STatistics (PAST) software (Natural History Museum, Oslo University, Norway). Multivariate neighborjoining cluster analyses with similarity-distances were calculated using correlation algorithm in PAST software (Feltens et al., 2010). Cluster analysis was saved as a Nexus file and imported into FigTree software to generate a circular tree. For sequencing analyses, genomic DNA (gDNA) of each of the selected isolates was prepared as in Chen and Kuo (1993). Amplifications of the $16 \mathrm{~S}$ rDNA, ITS, nifH, and rpoB sequences were carried out on a T-Gradient thermocycler (Biometra, Göttingen, Germany) in $50 \mu \mathrm{l}$ PCR reactions containing $50 \mathrm{ng}$ of gDNA, $0.2 \mathrm{mM}$ dNTPs, 1 unit Taq polymerase and $1 \mu \mathrm{M}$ final concentration of each of the corresponding primers listed in Table S2. Prior to sequencing, amplified products were separated onto agarose gels and purified using the NucleoSpin gel and PCR clean-up kit (MachereyNagel AG, Oensingen, Switzerland). Purified amplicons were sequenced at Microsynth AG (Balgach, Switzerland) using Sanger sequencing. High quality sequences were assembled into double stranded DNA sequences that were manually curated for ambiguous nucleotide positions and primer sequences. Except for strains CI-16A, CI-34D1, and CI-34F for which only $16 \mathrm{~S}$ rDNA sequences were obtained, the corresponding $16 \mathrm{~S}$ and ITS sequences of selected nodule isolates were deposited in GenBank as assembled 16S-ITS-partial 23S sequences. All DNA sequences used in this study were deposited in GenBank under the accession numbers that are listed in Table S2.

\section{Phylogenetic Analyses}

Putative phylogenetic relationships were inferred with the MEGA software version 6 (Tamura et al., 2013) using DNA sequences of selected isolates listed in Table S2. The corresponding 16SITS-23S, nifH, and $r p o B$ sequences of the reference strains Bradyrhizobium genosp. CB756, B. diaozoefficiens USDA $110^{\mathrm{T}}, B$. elkanii USDA $76^{\mathrm{T}}$ and USDA 3259, B. japonicum USDA $6^{\mathrm{T}}$, and B. pachyrhizi BR3262 were retrieved from GenBank. Reference strains were selected on the basis of taxonomic proximity to pigeonpea isolates and for best anchoring of tree branches. DNA sequences were aligned with ClustalW (for nifH and $r p o B$ ) or MUSCLE (for rRNA operon sequences) as implemented in MEGA, and manually corrected when needed. Phylogenetic trees were inferred using the neighbor-joining (NJ) method with statistical support calculated from 1000 bootstrap replicates. The best-fit nucleotide substitution model was selected according to the Bayesian information criterion (Schwarz, 1978): Tamura-Nei + Gamma (TN93+G) parameters for rpoB and 16S-ITS-23S sequences and Tamura $3+$ Gamma $(\mathrm{T} 92+\mathrm{G})$ parameters for 
TABLE 1 | Geographic positions and main characteristics of $C$. cajan sampled fields.

\begin{tabular}{|c|c|c|c|c|c|}
\hline \multirow[t]{2}{*}{ Locality } & \multirow[t]{2}{*}{ Field } & \multirow[t]{2}{*}{ Position } & \multirow[t]{2}{*}{ Vegetation cover } & \multicolumn{2}{|c|}{ Sampled } \\
\hline & & & & Plants & Nodules \\
\hline \multirow[t]{2}{*}{ Kossou-Bouafla } & 1 & $\begin{array}{l}\text { N } 7^{\circ} 17^{\prime} 45^{\prime \prime} \\
\text { W } 5^{\circ} 49^{\prime} 00^{\prime \prime}\end{array}$ & unplowed 8 years-old fallow with sparse $C$. cajan trees. & 5 & 26 \\
\hline & 2 & $\begin{array}{l}\text { N } 7^{\circ} 18^{\prime} 23^{\prime \prime} \\
\text { W } 5^{\circ} 49^{\prime} 06^{\prime \prime}\end{array}$ & unplowed 8 years old fallow with dense C. cajan cover. & 5 & 26 \\
\hline \multirow[t]{2}{*}{ Yamoussoukro } & 3 & $\begin{array}{l}\text { N } 6^{\circ} 51^{\prime} 19^{\prime \prime} \\
\text { W } 5^{\circ} 14^{\prime} 38^{\prime \prime}\end{array}$ & sparse 3-4 years old C. cajan plants in unkept backyard. & 3 & 11 \\
\hline & 4 & $\begin{array}{l}\text { N } 6^{\circ} 51^{\prime} 02^{\prime \prime} \\
\text { W } 5^{\circ} 13^{\prime} 31^{\prime \prime}\end{array}$ & 3 years-old plowed field of C. cajan intercropped with Jatropha curcas. & 4 & 21 \\
\hline \multirow[t]{2}{*}{ Bondoukou } & 5 & $\begin{array}{l}\text { N } 7^{\circ} 55^{\prime} 28^{\prime \prime} \\
\text { W } 2^{\circ} 57^{\prime} 45^{\prime \prime}\end{array}$ & 1 year-old plowed field of C. cajan intercropped with Dioscorea sp. & 6 & 48 \\
\hline & 6 & $\begin{array}{l}\text { N } 7^{\circ} 56^{\prime} 50^{\prime \prime} \\
\text { W } 2^{\circ} 56^{\prime} 26^{\prime \prime}\end{array}$ & 1 year-old unplowed field inter-cropped with Manihot esculenta. & 5 & 39 \\
\hline
\end{tabular}

nifH. In all trees, a corresponding sequence of $S$. fredii strain NGR234 was used as outgroup.

\section{Plant Assays}

Seeds of C. cajan cultivars ILRI 16555 and "Light Brown" were surface-sterilized using concentrated sulphuric acid for $10 \mathrm{~min}$, $0.1 \%(\mathrm{v} / \mathrm{v})$ Tween 20 for $5 \mathrm{~min}$ and $5 \%$ hydrogen peroxide for $5 \mathrm{~min}$, with intermediate washing steps using sterile $\mathrm{ddH}_{2} \mathrm{O}$. Seeds of Leucaena leucocephala, Macroptilium atropurpureum cv. Siratro, Tephrosia vogelii, Vigna radiata cv. King, and Vigna unguiculata cv. Red Caloona were surface sterilized as described previously (Fumeaux et al., 2011). To germinate, surfacesterilized seeds were incubated for two to three days in the dark, at $27^{\circ} \mathrm{C}$ and on $\mathrm{B} \& \mathrm{D}$ agar plates. Once germinated, seedlings were planted in Magenta jars (two plants per jar) containing vermiculite (Lewin et al., 1990), and watered using nitrogen-free B\&D solution (Broughton and Dilworth, 1971). When plantlets emerged from the vermiculite, each of them was inoculated with $200 \mu \mathrm{l}$ of a water solution containing $2 \times 10^{8}$ freshly grown bacteria. Plants were grown in controlled conditions with a light phase of $12 \mathrm{~h}$, a day temperature of $27^{\circ} \mathrm{C}$, a night temperature of $20^{\circ} \mathrm{C}$ and $60-70 \%$ humidity. Except when stated otherwise, plants were harvested at 42 days post inoculation (dpi). Symbiotic proficiency of each inoculant was assessed using as parameters the nodule number, total nodule fresh weight, dry weight of shoots, and presence/absence of leghemoglobin inside nodules or pseudonodules. The promiscuous $S$. fredii strain NGR234 was used as a control inoculum since it was shown to nodulate and fix nitrogen with all plants tested in this study (Perret et al., 1999; Pueppke and Broughton, 1999). Identity of each inoculant was confirmed by PCR amplification of ITS sequences using ITS-For2 and ITS-Rev2 primers and aliquots of nodule lysates as template.

\section{Scanning Electron Microscopy}

To minimize changes in cell structures, bacteria were fixed directly on an agar plate, for $1 \mathrm{~h}$ at room temperature using a final concentration of glutaraldehyde of $2 \%(\mathrm{v} / \mathrm{v})$. After three successive washes with $1 \mathrm{ml}$ of $66 \mathrm{mM}$ Sörensen's sodium phosphate buffer $\left(\mathrm{KH}_{2} / \mathrm{Na}_{2} \mathrm{HPO}_{4} 2 \mathrm{H}_{2} \mathrm{O}\right.$, pH 6.8), cells were postfixed in $2 \%(\mathrm{w} / \mathrm{v})$ osmium tetroxide solution for $1 \mathrm{~h}$. After another wash with Sörensen's buffer, samples were dehydrated by successive immersions of $10 \mathrm{~min}$ in solutions of respectively 25 , 50,75 , and $95 \%(\mathrm{v} / \mathrm{v})$ ethanol at $4^{\circ} \mathrm{C}$. Samples were then washed three times for $10 \mathrm{~min}$ in $100 \%$ ethanol at room temperature, and finally incubated in isoamyl acetate for $1 \mathrm{~h}$. Dehydrated samples were then mounted on aluminum mounts with silicon wafers, coated with gold and observed with a JEOL JSM 7001FA field emission scanning microscope.

\section{Basic Soil Properties}

Physical and chemical properties of soil samples were determined by a commercial soil analysis laboratory (Soil-Conseil, Gland, Switzerland) using standard methods (ISO 17025). Briefly, samples were homogenized, dried for $48 \mathrm{~h}$ at $40^{\circ} \mathrm{C}$ and sieved with fraction $<2 \mathrm{~mm}$ being used for subsequent analyses. Soil texture was determined by sedimentation once the humus was destroyed by $\mathrm{H}_{2} \mathrm{O}_{2}$. Soil type was determined using the standard USDA particle-size classification. Soluble elements $(\mathrm{Ca}, \mathrm{Cu}, \mathrm{Fe}, \mathrm{K}$, $\mathrm{Mg}, \mathrm{Mn}, \mathrm{P}$, and $\mathrm{Zn}$ ) were extracted with water and composition determined by spectrophotometry and spectrometry. $\mathrm{pH}$ was measured using $20 \mathrm{~g}$ of $2 \mathrm{~mm}$ sieved soil samples stirred in $50 \mathrm{ml}$ ultrapure $\mathrm{H}_{2} \mathrm{O}$. Organic matter (\%) was determined by oxidizing soil carbon with a mixture of $\mathrm{K}_{2} \mathrm{Cr}_{2} \mathrm{O}_{7} 1 \mathrm{~N}$ and $\mathrm{H}_{2} \mathrm{SO}_{4}$ 95-98\%, total nitrogen (\%) was measured using the Kjeldhal method, and available nitrogen was extracted with $0.01 \mathrm{M} \mathrm{CaCl}_{2}$ solution and measured by spectrophotometry.

\section{RESULTS}

\section{Characteristics of Sampled Fields}

Two separate fields were sampled in each of the three localities that were selected for their different records of $C$. cajan cultivation (see Figure 1). Close to the northeast city of Bondoukou, next to the border with Ghana, cultivation of pigeonpea has been established for many years with inhabitants having given vernacular names in local dialects to this crop (e.g., "Kapkô" in Koulango). The two sampled fields of Bondoukou 


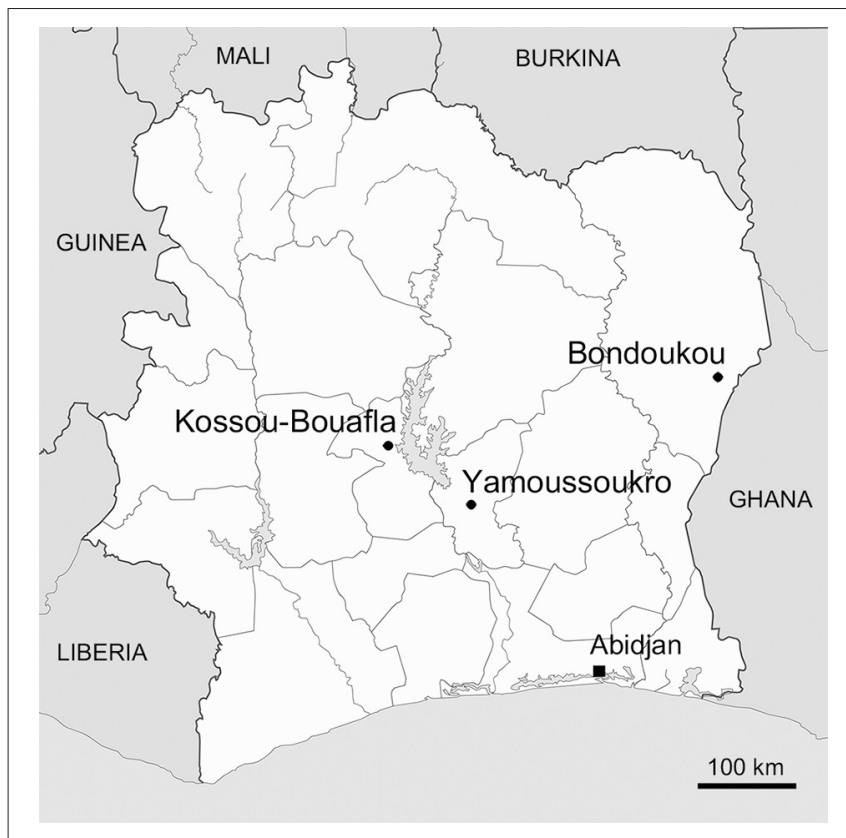

FIGURE 1 | Regional map of Côte d'Ivoire with positions of the three sampled sites. Geographic coordinates in degrees, minutes, and seconds of the sampled fields in Kossou-Bouafla, Yamoussoukro, and Bondoukou are given in Table 1

covered an area of 0.5 and 2 ha, and were intercropped with yam (Dioscorea sp.) and cassava (Manihot esculenta), respectively. In this area of Côte d'Ivoire, seeds of pigeonpea found on local markets had diverse sizes and colors (ranging from whitish to brown), indicating that farmers favored growth of different landraces rather than a specific cultivar. This contrasted with the C. cajan plants grown in the two fields of Kossou-Bouafla and that were exclusively offsprings of the ILRI 16555 cultivar. ILRI 16555 was introduced in 2004 via a program sponsored by the Heifer International charity for fostering the use of perennial cultures of pigeonpea as forage to cattles in cotton-based agricultural systems. Accordingly, seeds held by farmers in Kossou-Bouafla were uniformly brown. The remaining two fields of 0.5 and 1.5 ha, were sampled in the outskirts of the capital Yamoussoukro. They were used for planting uncharacterized cultivars of C. cajan. The field covering 1.5 ha was intercropped with Jatropha curcas plants, and was used for producing pigeonpea seeds for poultry feeding. In each of the six sampled fields and within $1.5 \mathrm{~m}$ from the trunk, root systems of three to six plants were cleared of soil. Only nodules attached to the cleared root system were collected. Once cleared of most soil particles, nodules that belonged to the same root system were stored together into a single desiccating vial and kept at $4^{\circ} \mathrm{C}$ until further processing. In total, 171 root nodules belonging to 28 plants were collected in the six designated fields.

\section{Isolation and MALDI-TOF MS Characterisation of Nodule Bacteria}

A total of 85 nodule isolates were recovered and purified as single colonies. Initial identification was performed with MALDI-TOF
MS as in Ziegler et al. (2015). Mass spectral analyses did not only provide a preliminary identity at the genus or species level for most of the nodule isolates, but also allowed for a cluster analysis of MS signatures. As shown in Figure 2, 62 isolates (73\%) clustered into two clearly separated groups of strains (clusters I and II). The larger of these two groups included the reference $B$. elkanii strains USDA $76^{\mathrm{T}}$ and USDA 3259 as well as 43 isolates of C. cajan nodules (lower left quadrant in Figure 2). The second cluster consisted of 19 closely related isolates (Figure 2, upper left quadrant) identified by MALDI-TOF MS as bradyrhizobia sp. The remaining 23 isolates were extremely diverse (Figure 2, upper-right corner), with only three strains (CI-5B, -39Bx, and CI-41A) sharing rhizobia-like features (Table S1).

\section{S rRNA Gene Sequencing to Confirm the Identities of Nodule Isolates}

To verify that the initial identification and clustering of nodule bacteria was accurate, several isolates were selected on the basis of (i) their respective position in the cluster tree shown in Figure 2, (ii) the field/soil in which nodules were found, and (iii) the bacterial identification (or absence of it) obtained via MALDITOF MS. Accordingly, a subset of 8 strains (CI-1A, -7A, -15C, $-19 \mathrm{~F},-33 \mathrm{M},-36 \mathrm{~B},-36 \mathrm{E}$, and $\mathrm{CI}-40 \mathrm{~F}$ ) was selected amongst the 43 isolates initially identified as $B$. elkanii (cluster I). CI-1B, $-14 \mathrm{~A},-19 \mathrm{D},-33 \mathrm{~F}$, and CI-41S were chosen to represent the 19 bradyrhizobia that formed the second cluster of related strains, and six (CI-5B, -16A, -34D1, -34F, -39Bx, and CI-41A) of the 23 unrelated strains were retained for $16 \mathrm{~S}$ rDNA sequencing. Except for strains CI-5B and CI-39Bx, of which the 16S genes matched those of Rhizobium leguminosarum bv. viciae and Rhizobium sp. strain JGI 0001005-K05 respectively, 16S rDNA sequencing confirmed the identifications obtained with mass spectra analyses (see Table S1). For example, the 8 isolates selected from cluster I were found to carry $16 \mathrm{~S}$ rRNA genes identical to those of several members of the B. elkanii super clade (Aserse et al., 2012) including B. elkanii type strain USDA $76^{\mathrm{T}}$, B. pachyrizi strain $\mathrm{PAC} 48^{\mathrm{T}}$ and Bradyrhizobium tropiciagri CNPSo $1112^{\mathrm{T}}$. Isolates CI-1B, $-14 \mathrm{~A},-19 \mathrm{D},-33 \mathrm{~F}$, and CI-41S of cluster II shared identical $16 \mathrm{~S}$ ribosomal sequences that were $99.7 \%$ similar to the same type strains USDA $76^{\mathrm{T}}, \mathrm{PAC} 48^{\mathrm{T}}$ and CNPSo $1112^{\mathrm{T}}$, while the extremely slow-growing isolate CI-41A was found to be closely related to $B$. liaoningense. As to isolates CI-16A, -34D1, and $\mathrm{CI}-34 \mathrm{~F}$ that were not identified via MALDI-TOF mass spectrometry, the respective $16 \mathrm{~S}$ rRNA sequences best matched those of Paenibacillus sp. JDR-2 (accession number CP001656.1), Brevibacillus reuszeri DSM 9887 (LGIQ01000014.1) and Bacillus soli strain NBRC 102451 (BCVI01000121.1). These analyses further confirmed that, for those strains for which a related reference existed in the spectral databases, MALDI-TOF MS provided an accurate identification (Ziegler et al., 2015).

\section{Assessing Diversity of C. cajan Isolates with ITS and nifH Sequences}

Although selected isolates from the same cluster shared identical $16 \mathrm{~S}$ rDNA sequences, topology of the cladogram shown in Figure 2 suggested genetic diversity existed within each of these 


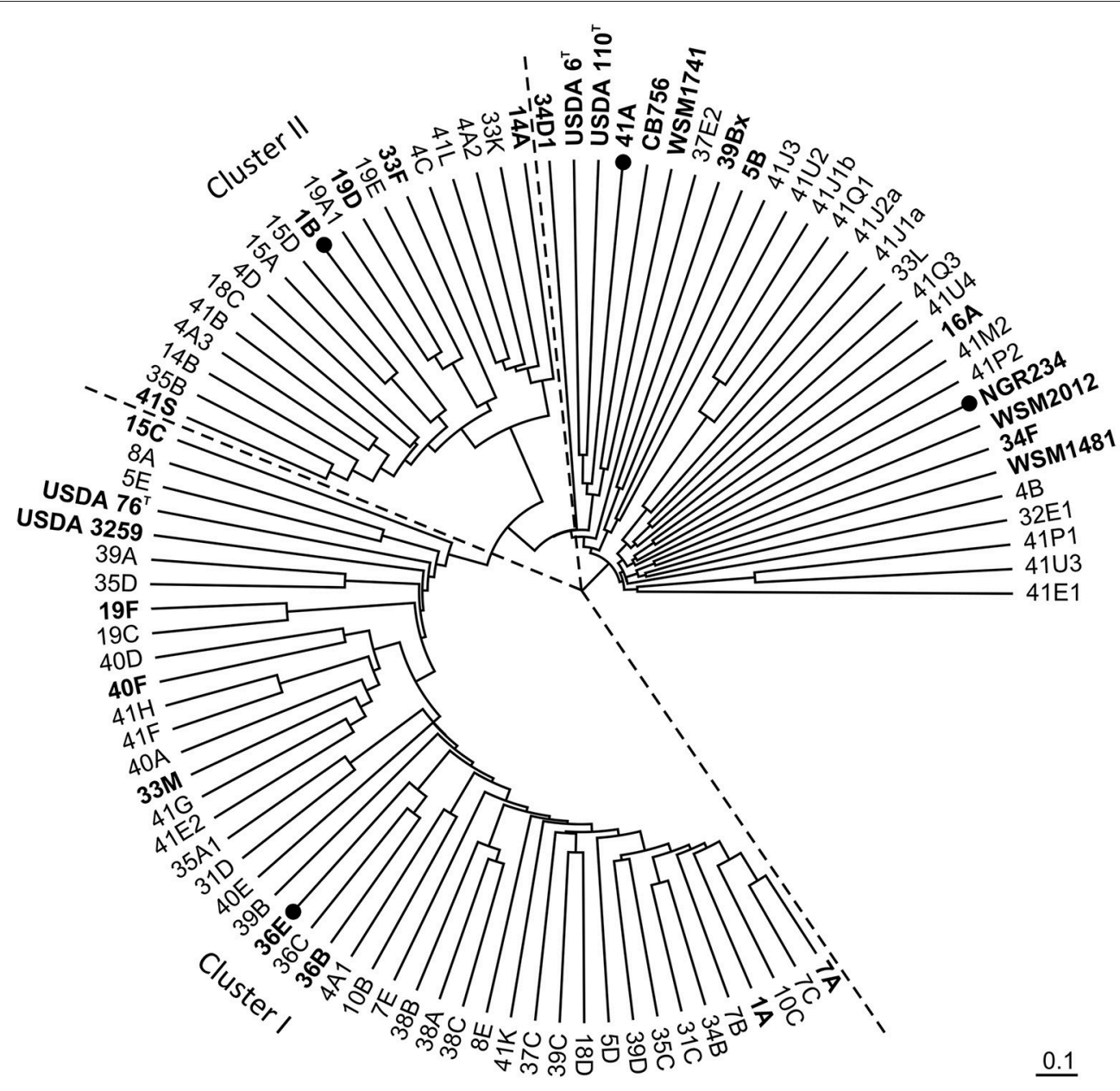

FIGURE 2 | Unsupervised hierarchical cluster analysis of MALDI-TOF MS signatures for nodules isolates and selected reference strains using the characteristic protein masses comprised between $\mathbf{m} / \mathbf{z} 3$ and $\mathbf{1 5} \mathbf{k D a}$ that are listed in Table S5. Nodule isolates from Côte d'Ivoire (Cl-) are only referred to by the strain number. Reference strains Bradyrhizobium sp. WSM1741, Bradyrhizobium genosp. CB756, B. diaozoefficiens USDA 110 ${ }^{\top}$, B. elkanii USDA 76 ${ }^{\top}$ and USDA 3259, B. japonicum USDA $6^{\top}$, Rhizobium leguminosarum bv. viciae WSM1481, R. leguminosarum bv. trifolii WSM2012, S. fredii NGR234 as well as nodule isolates for which DNA sequences were obtained are marked in bold. Strains for which symbiotic proficiency on C. cajan was reported in Table $\mathbf{2}$ are marked with a black circle. Dashed lines delimitate the two major clusters of nodule isolates.

clusters. To examine whether selected isolates from clusters I (8 out of 43 strains) and II (5 out of 19) differed genetically, the internal transcribed spacer (ITS) separating $16 \mathrm{~S}$ and $23 \mathrm{~S}$ rRNA genes as well as the nifH gene that codes for the structural Fe protein of nitrogenase were amplified and sequenced. Strains CI-5B, -39Bx, and CI-41A were also included in these analyses because all three isolates possessed rhizobia-like features (see Table S1). For many years, the ITS region has been used in population genetics and molecular systematics (Gürtler and Stanisich, 1996), in particular for taxa for which 16S rRNA gene sequences lacked resolution for closely related isolates [e.g., sphingomonads (Tokajian et al., 2016)]. NifH is an essential component of the nitrogenase complex, and its gene has been widely used to survey diazotrophs in diverse ecosystems (Zehr et al., 2003).

Once deleted of the flanking $16 \mathrm{~S}$ and $23 \mathrm{~S}$ rRNA sequences, the amplified ITS regions of the 16 selected nodule isolates ranged in size from 760 bp (CI-41A) to 1054 bp (CI-5B) (Table S2). Comparing these amplified ITS sequences confirmed that isolates of the B. elkanii cluster I were not genetically identical: CI-15C and CI-19F shared similar ITS sequences (4 mismatches over 910 nucleotides) that were longer and differed significantly from those of the remaining six isolates ( 801 and $802 \mathrm{bp}$ long). ITS's of CI-1A, $-33 \mathrm{M}$, and CI-36E were identical and formed a consensus sequence, from which the ITS's of CI-7A and CI-40F differed by only one nucleotide while that of CI-36B diverged by seven bases. By contrast, and except for the one nucleotide-shorter ITS of CI-19D, ITS's of selected isolates from cluster II were 862 bp long and differed by a maximum of only six nucleotide positions. ITS regions of CI-1B and CI-33F were identical and appeared as possibly more ancient, with that of CI-41S being the most divergent of all five selected isolates. Thus, ITS analyses confirmed that, when compared to the five isolates of cluster II that showed little diversity, strains of cluster I were more diverse 


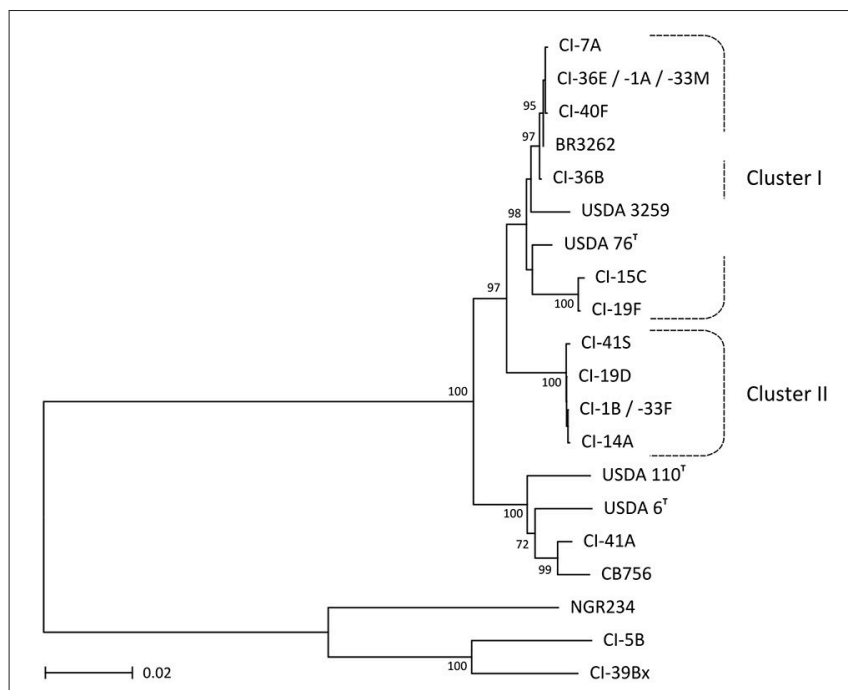

FIGURE 3 | Phylogenetic tree inferred from rRNA operon sequences corresponding to nearly complete $16 \mathrm{~S}$ rRNA, full ITS and $5^{\prime}$-end of $23 S$ rRNA sequences for a selected subset of $16 \mathrm{C}$. cajan nodule isolates (marked as $\mathbf{C l}-$ strains) and 7 reference rhizobia. Phylogenetic tree was obtained with the NJ method, with bootstrap values issued from 1000 repetitions and only shown for those $\geq 70$. Dashed lines mark the boundaries of the strain clusters I and II identified via MALDI-TOF mass-spectra analyses.

and could be further subdivided into two distinct groups: a set of closely related isolates (CI-1A, $-7 \mathrm{~A},-33 \mathrm{M},-36 \mathrm{~B},-36 \mathrm{E}$, and $40 \mathrm{~F}$ ) with CI-19F and CI-15C forming a more distantly related outgroup. These various subgroups of nodule isolates can be clearly observed in the unrooted-phylogeny trees of 16S-ITS and partial $23 \mathrm{~S}$ as well as $r p o B$ sequences shown in Figure 3 and Figure S1.

Diversity of selected isolates was further confirmed by comparing nifH sequences. With a maximum of four diverging nucleotide positions, $\mathrm{NifH}$ coding sequences of selected cluster II isolates (CI-1B, -14A, -19D, -33F, and CI-41S) were closely related to and did best match the nifH gene of $B$. elkanii type strain USDA 76 (see Figure 4). In contrast, nifH sequences of cluster I strains fell into two distinct subgroups, one of which included isolates CI-15C and CI-19F. Unlike what was observed in the 16SITS-23S phylogenetic tree (Figure 3), nifH of CI-15C and CI$19 \mathrm{~F}$ were closer to corresponding sequences of cluster II isolates than to those of the remaining cluster I strains (see Figure 4). In fact, the best match for nifH of CI-1A, -7A, $-33 \mathrm{M},-36 \mathrm{~B}$, $36 \mathrm{E}$, and CI-40F was the corresponding gene of Bradyrhizobium pachyrhizi strain BR3262. As in Figure 3, CI-41A stood out from cluster I and cluster II isolates, with a best match for nifH in Bradyrhizobium genosp. CB756 (SA-4). Thus, except for the discrepant nifH of CI-15C and CI-19F, the 16S-ITS-partial 23S and nifH phylogenies were similar.

\section{Testing the Symbiotic Properties of a Subset of C. cajan Nodule Isolates}

Proficiency of representative CI-1B (for cluster II), CI-36E (cluster I), CI-41A (Bradyrhizobium sp. isolate) and control NGR234 strains was compared using offsprings of self-crossed

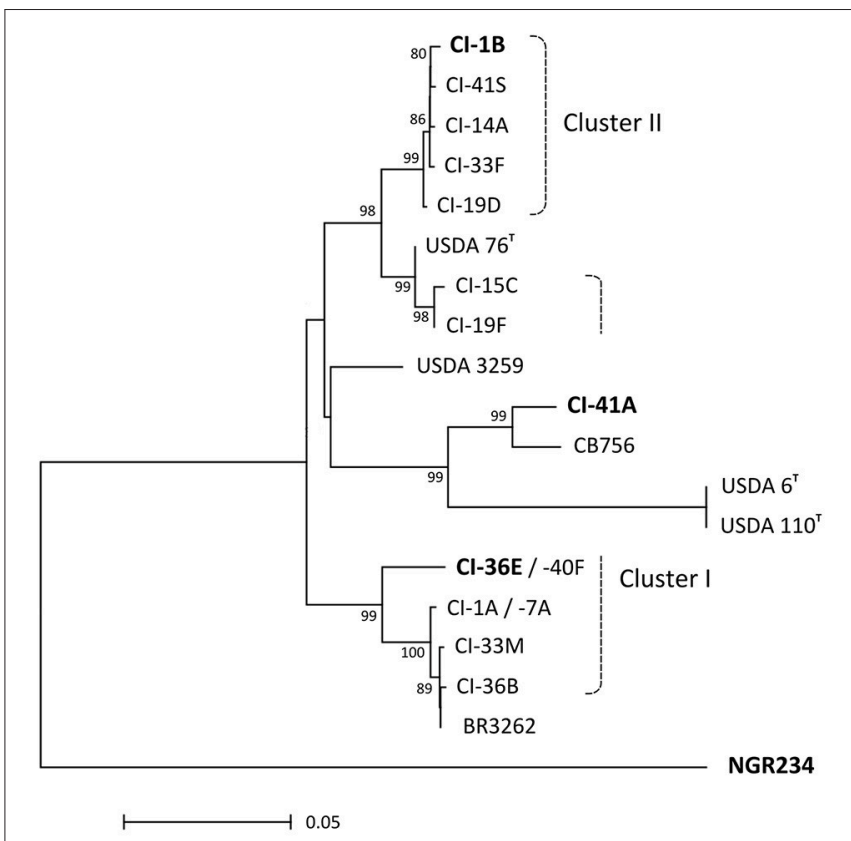

FIGURE 4 | Phylogenetic tree inferred from nifH genes of selected $\mathbf{C}$. cajan nodule isolates ( $\mathrm{Cl}$ - strains) and 7 reference rhizobia. Phylogenetic tree was obtained with the $\mathrm{NJ}$ method, with bootstrap values issued from 1000 repetitions and only shown for those $\geq 75$. Dashed lines delimit the boundaries of the strain clusters I and II identified via MALDI-TOF

mass-spectra analyses. The discrepant position of $\mathrm{Cl}-41 \mathrm{~A}$ and related reference $\mathrm{CB} 756$ strains, highlights the separation of $\mathrm{Cl}-15 \mathrm{C}$, and $\mathrm{Cl}-19 \mathrm{~F}$ from the remaining strains of cluster $\mathrm{I}$. Strains tested for symbiotic proficiency on $C$. cajan and reported in Table 2 are shown in bold. No nifH amplicon was obtained for the non-symbiotic isolates $\mathrm{Cl}-5 \mathrm{~B}$ and $\mathrm{Cl}-39 \mathrm{Bx}$.

ILRI 16555 and "Light Brown" plants collected in Côte d'Ivoire. As shown in Table 2 and Figure S2, pigeonpea isolates were clearly more proficient symbionts than NGR234 on the selected C. cajan cultivars, with a shoot dry weight for plants inoculated with CI-1B, $-36 \mathrm{E}$, and CI-41A being at least twice as much as that of plants nodulated by NGR234. While symbiotic efficacies of CI$1 \mathrm{~B}$ and CI-41A were found to be similar on both ILRI 16555 and "Light Brown" cultivars, CI-36E appeared slightly less efficient. Interestingly, on both ILRI 16555 and "Light Brown" cultivars NGR234 made fewer (Table 2, Figure S2) but larger nodules. For example on ILRI 16555 (test \#2), NGR234 formed nodules of ca. $32 \mathrm{mg}$ fresh weight each whereas plants inoculated with isolates CI-1B, -36E, and -41A carried nodules of 9.4-12.1 mg fresh weight in average. Thus, when compared to pigeonpea isolates, the lower symbiotic efficacy of NGR234 on C. cajan possibly resulted from a reduced ability to initiate nodule formation rather than a lower nitrogen fixation capacity once bacteria were established inside nodules.

A number of additional but smaller scale nodulation assays were also carried out in order to better define the host-range and nodulation properties of pigeonpea isolates (Tables S3-A and S3-B). In addition to ILRI 16555 and "Light Brown" cultivars, the selected CI-1B, $-36 \mathrm{E}$, and CI-41A isolates were also found to nodulate $(\mathrm{Nod}+)$ and fix nitrogen $(\mathrm{Fix}+)$ with Macroptilium atropurpureum cv. Siratro, Tephrosia vogelii, Vigna unguiculata 
TABLE 2 | Symbiotic properties of selected strains on two C. cajan cultivars grown under controlled conditions for 42 days post-inoculation.

\begin{tabular}{|c|c|c|c|c|c|c|c|c|c|}
\hline \multirow[t]{2}{*}{ Inoculum } & \multirow[t]{2}{*}{ Assay } & \multicolumn{4}{|c|}{ C. cajan cv. ILRI 16555} & \multicolumn{4}{|c|}{ C. cajan cv. "Light Brown" } \\
\hline & & Plants & $\mathrm{mNN}$ & mNFW (mg) & mSDW (mg) & Plants & $\mathrm{mNN}$ & mNFW (mg) & mSDW (mg) \\
\hline \multirow[t]{2}{*}{ No bacteria } & 1 & 8 & 0.0 & 0.0 & $120.8( \pm 26.8)$ & 8 & 0.0 & 0.0 & $74.4( \pm 47.9)$ \\
\hline & 2 & 12 & 0.0 & 0.0 & $123.2( \pm 40.6)$ & 10 & 0.0 & 0.0 & $50.8( \pm 17.2)$ \\
\hline \multirow[t]{2}{*}{$\mathrm{Cl}-1 \mathrm{~B}$} & 1 & 12 & $91.7( \pm 22.8)$ & $973.0( \pm 391.5)$ & $2003.5( \pm 661.1)$ & 11 & $56.5( \pm 17.7)^{f}$ & $1061.9( \pm 221.4)$ & $1841.3( \pm 439.6)^{h}$ \\
\hline & 2 & 13 & $119.6( \pm 63.0)^{a}$ & $1150.0( \pm 449.5)^{b}$ & $2521.8( \pm 803.2)^{d}$ & 14 & $61.5( \pm 20.6)$ & $1116.7( \pm 324.7)^{i}$ & $2093.3( \pm 695.9)$ \\
\hline \multirow[t]{2}{*}{$\mathrm{Cl}-36 \mathrm{E}$} & 1 & 12 & $91.3( \pm 46.4)$ & $792.8( \pm 203.6)$ & $2073.6( \pm 489.6)$ & 12 & $77.6( \pm 26.4)^{f, g}$ & $866.8( \pm 265.1)$ & $1465.6( \pm 373.6)^{h}$ \\
\hline & 2 & 16 & $76.3( \pm 38.2)^{\mathrm{a}}$ & $717.3( \pm 232.3)^{\mathrm{b}, \mathrm{c}}$ & $1814.0( \pm 466.8)^{d, e}$ & 16 & $79.9( \pm 32.1)$ & $821.5( \pm 208.2)^{i, j}$ & $1701.4( \pm 508.1)$ \\
\hline \multirow[t]{2}{*}{ Cl-41A } & 1 & 12 & $73.7( \pm 17.2)$ & $902.2( \pm 410.6)$ & $1932.4( \pm 741.9)$ & 12 & $53.3( \pm 19.8)^{9}$ & $942.0( \pm 226.8)$ & $1745.8( \pm 402.1)$ \\
\hline & 2 & 16 & $82.8( \pm 42.0)$ & $999.8( \pm 481.3)^{\mathrm{C}}$ & $2347.9( \pm 905.3)^{\mathrm{e}}$ & 14 & $64.8( \pm 25.7)$ & $1039.2( \pm 311.1)^{j}$ & $2011.4( \pm 621.9)$ \\
\hline \multirow[t]{2}{*}{ NGR234 } & 1 & 12 & $10.1( \pm 4.1)$ & $455.1( \pm 220.1)$ & $959.6( \pm 358.1)$ & 11 & $4.2( \pm 1.9)$ & $219.7( \pm 104.9)$ & $359.8( \pm 115.3)$ \\
\hline & 2 & 15 & $10.2( \pm 4.1)$ & $326.5( \pm 134.6)$ & $751.9( \pm 307.5)$ & 13 & $6.8( \pm 4.6)$ & $202.1( \pm 98.8)$ & $328.8( \pm 158.1)$ \\
\hline
\end{tabular}

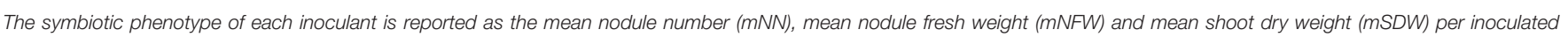

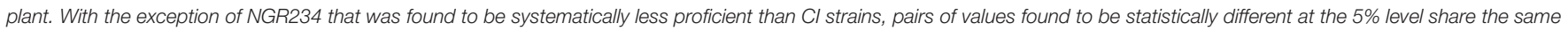
superscript letter.

cv. Red Caloona (Table S3-A) and Vigna radiata cv. King (Table S3-B). On Leucaena leucocephala that forms Fix + associations with NGR234 (Lewin et al., 1990), strains CI-1B, CI-36E, and CI$41 \mathrm{~A}$ were found to induce only few pseudonodules that appeared to be Fix-, however. By contrast, isolates CI-5B and CI-39Bx failed to nodulate any of the hosts that were so far tested: a result consistent with the absence of successful nifH amplifications for both of these isolates.

\section{DISCUSSION}

A total of more than 170 nodules of C. cajan were collected in three regions and six fields of Côte d'Ivoire. In fields 14 of Kossou-Bouafla and Yamoussoukro, roots of pigeonpea plants carried few nodules, many of which were senescent and contained no viable rhizobia. Nevertheless, 85 isolates were recovered of which 63 were found to belong to bradyrhizobia species as shown by MALDI-TOF MS and sequencing analyses. In fact, except for the extremely slow growing isolate CI-41A related to $B$. liaoningense, the other 62 bradyrhizobia fell into two major phyletic clusters. With 43 members, cluster I was found to include at least two types of isolates found to be related to distinct B. elkanii-like strains: CI-1A, -7A, $-33 \mathrm{M},-36 \mathrm{~B},-36 \mathrm{E}$, and CI-40F formed one subgroup while the CI-15C and CI-19F formed a second subgroup of isolates. In fact $16 \mathrm{~S}$ rDNA-ITS-23S rDNA sequencing confirmed that the six isolates CI-1A to CI-40F were closely related to a recently sequenced strain isolated in Brazil and referred to as B. pachyrhizi BR3262 (Simões-Araújo et al., 2016), whereas the second subgroup made of CI-15C and CI-19F-like isolates was found to be more closely related to B. elkanii USDA $76^{\mathrm{T}}$ (see Figure 3). Whether these two subgroups of cluster I isolates indeed belong to taxonomically distinct species remains to be determined, but nodulation assays showed that symbiotic proficiency of CI-36E and CI-15C differed notably on $V$. radiata cv. King (Table S3-B). These findings support the proposal by Aserse et al. (2012) and others (Vinuesa et al., 2008; Menna et al., 2009) that B. elkanii constitutes a super clade of microorganisms rather than a monophyletic species. In contrast, cluster II isolates appeared to be genetically more homogenous with for example the nifH sequences of bacteria being geographically as distant as CI-1B (isolated from field 1 in Kossou-Bouafla) and CI33F (field 5 in Bondoukou) differing by only three mismatches. Thus, isolates that were found to be symbiotically proficient on pigeonpea appeared to belong to four different groups of bradyrhizobia of which CI-36E (cluster I, related to B. pachyrhizi BR3262), CI-15C (cluster I, related to B. elkanii USDA $76^{\mathrm{T}}$ ), CI1B (cluster II, Bradyrhizobium sp.) and CI-41A (extremely slow growing, $B$. liaoningense) were selected as representative strains.

By contrast, none of the remaining 22 non-bradyrhizobia isolates was found to nodulate C. cajan, even though CI-5B and CI-39Bx were identified as putative Rhizobium spp. by MALDITOF MS and/or 16S rDNA sequence analyses. Interestingly, scanning electron micrographs showed that CI-5B cell surface differed significantly from that of CI-1B, $-36 \mathrm{E}$ and CI-41A (see Figure S3). Whether surface polysaccharides, which often contribute to define symbiotic properties, are responsible for such difference remains to be confirmed. nifH amplifications repeatedly failed for CI-5B and CI-39Bx and neither strains formed nodules on $C$. cajan cultivars or any of the legumes tested so far. Taken together these results suggest that CI-5B and CI-39Bx are possibly rhizobia on the making. Whether CI$5 \mathrm{~B}$ and/or CI-39Bx have lost or not yet acquired genes essential for symbiosis remains to be determined, but genomic studies and mobilization of known symbiotic elements may provide conclusive answers. Whether non-bradyrhizobial nodule isolates represent contaminating soil bacteria or true nodule endophytes remains uncertain. While reports describing the isolation from root nodules of non-nodulating bacteria are becoming more frequent (Muresu et al., 2008; Deng et al., 2011; Wu et al., 2011; De Meyer and Willems, 2012), little data has documented opportunistic infections (Pandya et al., 2013; Zgadzaj et al., 2015). During isolation of bacteria from pigeonpea nodules, no evidence of surface contaminants was found following surfacesterilization of nodules. As several isolates were identified as 
spore-forming bacteria including Bacillus megaterium (CI-41J1b, $-41 \mathrm{~J} 2 \mathrm{a},-41 \mathrm{Q} 1)$, B. subtilis (CI-41U2) and Brevibacillus reuszeri (CI-34D1) it cannot be excluded that spores, which are likely to resist nodule surface-sterilization procedures, germinated once nodules were squashed and rapidly overgrew endosymbiotic rhizobia. Thus, no strain growing faster than bradyrhizobia was identified amongst the current catalog of true pigeonpea symbionts from Côte d'Ivoire (Table S1).

Regardless of which field was sampled, and in spite of different records of pigeonpea cultivation for the three-targeted areas of Côte d'Ivoire, similar profiles of symbiotic strains were identified with more than two thirds of proficient nodule isolates being related to members of the $B$. elkanii super clade. No plantor cultivar-specific effect was identified as illustrated by plant $\mathrm{n}^{\circ} 41$ (collected in Bondoukou), which was indiscriminately nodulated by strains belonging to cluster I (5 isolates), cluster II (3) or by the single extra-slow growing isolate CI-41A. In contrast to fields of Bondoukou where pigeonpea roots carried numerous nodules, plants collected in fields of Kossou-Bouafla and Yamoussoukro had fewer nodules. To verify whether soil parameters such as $\mathrm{pH}$ and/or total nitrogen content were possibly responsible for the apparently low symbiotic responses observed in fields of central Côte d'Ivoire, we determined the physical and chemical properties of soil samples taken in fields 1, 2 (both in Kossou-Bouafla) and 4 (Yamoussoukro). As shown in Table S4, soil pH ranged from slightly acidic (6.3) to neutral (7.2) and thus was unlikely to block nodulation. Available nitrogen ranged from $20.4 \mathrm{~kg} / \mathrm{ha}$ (field $\mathrm{n}^{\circ} 1$ ) to $45.7 \mathrm{~kg} / \mathrm{ha}$ (field $\mathrm{n}^{\circ} 2$ ), but neither values were close to the $85 \mathrm{~kg} / \mathrm{ha}$ reported for optimal growth and production of pigeonpea (van der Maesen, 2006). Levels of organic matter were mostly adequate, with nitrogen/carbon ratios $<15$ suggesting good rates of organic matter decomposition. While potassium levels were adequate, phosphate concentrations were found to be low but not critically so. Thus, none of the soil parameters examined reached values susceptible to block nodulation in fields of Kossou-Bouafla and Yamoussoukro. Interestingly, NPK levels were highest in field $\mathrm{n}^{\circ} 2$ where smallholder farmers reported to have used shoot matter as a green manure. This result suggests that, in combination with improved nodulation by rhizobia, the persistent use of C. cajan as green manure during fallow may reduce the dependency of farmers on chemical fertilizers to boost plant productivity.

Perhaps the poor symbiotic responses observed in fields 1-4 resulted from low titers of symbiotic rhizobia in these soils. Although abundance of rhizobia was not measured in the soil

\section{REFERENCES}

Akanvou, R., Kropff, M. J., Bastiaans, L., and Becker, M. (2002). Evaluating the use of two contrasting legume species as relay intercrop in upland rice cropping systems. Field Crops Res. 74, 23-36. doi: 10.1016/S0378-4290(01)0 0198-8

Araujo, J., Diaz-Alcantara, C. A., Velazquez, E., Urbano, B., and GonzalezAndres, F. (2015). Bradyrhizobium yuanmingense related strains form nitrogenfixing symbiosis with Cajanus cajan L. in Dominican Republic and are efficient biofertilizers to replace N fertilization. Sci. Hortic. 192, 421-428. doi: 10.1016/j.scienta.2015.06.009 samples we collected, it was remarkable that in Bondoukou where pigeonpea has been cultivated for several decades root nodules were more abundant. If a low number of proficient rhizobia was indeed the factor limiting nodulation of C. cajan, a bio-inoculant prepared from either one or a combination of the selected bradyrhizobial isolates could possibly improve nodulation, symbiotic nitrogen fixation and eventually increase plant productivity. In this respect, isolates CI-1B (cluster II) and CI-36E (cluster I) share a number of features expected of a local bio-inoculant: both strains (i) belong to species that are ubiquitous and thus presumably well adapted to soils of Côte d'Ivoire, (ii) are symbiotically proficient on at least two C. cajan cultivars, and (iii) associate and fix nitrogen with additional legume crops frequently cultivated by smallholder farmers. Whether such important characteristics effectively translate into efficient nitrogen fixation during field tests remains to be tested.

\section{AUTHOR CONTRIBUTIONS}

Following an idea by $\mathrm{AZ}, \mathrm{XP}$ and $\mathrm{AZ}$ wrote a research proposal. $\mathrm{RF}, \mathrm{AZ}$ and XP carried out the sampling of pigeonpea nodules in fields of Côte d'Ivoire. Under the supervision of XP, RF carried out the isolation, genetic characterization and symbiotic assays of nodule bacteria. DZ analyzed nodule isolates by mass spectrometry. FB made the scanning electron micrographs. RF and XP wrote the manuscript.

\section{ACKNOWLEDGMENTS}

We would like to thank Natalia Giot for her help in many aspects of this work. Financial support was provided by the University of Geneva, the United Nations Development Program and the Swiss National Science Foundation (grant $n^{\circ} 31003 \mathrm{~A}-$ 146548). RF acknowledges the generous help of the Swiss Federal Commission for Scholarships for Foreign Students. We are also grateful to Carlos Javier Rivera-Rivera for his expert help in phylogenetic analyses, and to M. Poussy Sébé for providing valuable data on the introduction of ILRI 16555 cultivar in Côte d'Ivoire.

\section{SUPPLEMENTARY MATERIAL}

The Supplementary Material for this article can be found online at: http://journal.frontiersin.org/article/10.3389/fmicb. 2016.01793/full\#supplementary-material 
Broughton, W. J., and Dilworth, M. J. (1971). Control of leghaemoglobin synthesis in snake beans. Biochem. J. 125, 1075-1080. doi: 10.1042/bj12 51075

Broughton, W. J., Wong, C.-H., Lewin, A., Samrey, U., Myint, H., Meyer, H., et al. (1986). Identification of Rhizobium plasmid sequences involved in recognition of Psophocarpus, Vigna, and other legumes. J. Cell Biol. 102, 1173-1182. doi: $10.1083 /$ jcb.102.4.1173

Charpentier, H., Doumbia, S., Coulibaly, Z., and Zana, O. (1999). Fixation de l'agriculture au Nord et au centre de la Côte d'Ivoire: quels nouveaux systèmes de culture? Agric. Dév. 21, 41-70.

Chen, W. P., and Kuo, T. T. (1993). A simple and rapid method for the preparation of gram-negative bacterial genomic DNA. Nucleic Acids Res. 21:2260. doi: 10.1093/nar/21.9.2260

Degefu, T., Wolde-meskel, E., and Frostegård, Å. (2013). Phylogenetic diversity of Rhizobium strains nodulating diverse legume species growing in Ethiopia. Syst. Appl. Microbiol. 36, 272-280. doi: 10.1016/j.syapm.2013.03.004

De Meyer, S. E., and Willems, A. (2012). Multilocus sequence analysis of Bosea species and description of Bosea lupini sp. nov., Bosea lathyri sp. nov. and Bosea robiniae sp. nov., isolated from legumes. Int. J. Syst. Evol. Microbiol. 62( $\mathrm{Pt} 10)$, 2505-2510. doi: 10.1099/ijs.0.035477-0

Deng, Z. S., Zhao, L. F., Kong, Z. Y., Yang, W. Q., Lindström, K., Wang, E. T., et al. (2011). Diversity of endophytic bacteria within nodules of the Sphaerophysa salsula in different regions of Loess Plateau in China. FEMS Microbiol. Ecol. 76, 463-475. doi: 10.1111/j.1574-6941.2011.01063.x

Denton, M. D., Coventry, D. R., Murphy, P. J., Howieson, J. G., and Bellotti, W. D. (2002). Competition between inoculant and naturalised Rhizobium leguminosarum bv. trifolii for nodulation of annual clovers in alkaline soils. Aust. J. Agr. Res. 53, 1019-1026. doi: 10.1071/AR01138

Feltens, R., Görner, R., Kalkhof, S., Gröger-Arndt, H., and von Bergen, M. (2010). Discrimination of different species from the genus Drosophila by intact protein profiling using matrix-assisted laser desorption ionization mass spectrometry. BMC Evol. Biol. 10:95. doi: 10.1186/1471-2148-10-95

Fening, J. O., and Danso, S. K. A. (2002). Variation in symbiotic effectiveness of cowpea bradyrhizobia indigenous to Ghanaian soils. Appl. Soil Ecol. 21, 23-29. doi: 10.1016/S0929-1393(02)00042-2

Ferreira, L., Sánchez-Juanes, F., García-Fraile, P., Rivas, R., Mateos, P. F., Martínez-Molina, E., et al. (2011). MALDI-TOF mass spectrometry is a fast and reliable platform for identification and ecological studies of species from family Rhizobiaceae. PLoS ONE 6:e20223. doi: 10.1371/journal.pone.002 0223

Fossou, R. K., Kouassi, N. K. I., Kouadjo, G. C. Z., Zako, S. M. I. B., and Zézé, A. (2012). Diversité de rhizobia dans un champ cultivé de pois d'Angole (Cajanus cajan L.) à Yamoussoukro (Centre de la Côte d'Ivoire). Agronomie Afr. 24, 29-38.

Freiberg, C., Fellay, R., Bairoch, A., Broughton, W. J., Rosenthal, A., and Perret, X. (1997). Molecular basis of symbiosis between Rhizobium and legumes. Nature 387, 394-401. doi: 10.1038/387394a0

Fumeaux, C., Bakkou, N., Kopćinska, J., Golinowski, W., Westenberg, D. J., Müller, P., et al. (2011). Functional analysis of the nifQdctA1y4vGHIJ operon of Sinorhizobium fredii strain NGR234 using a transposon with a NifAdependent read-out promoter. Microbiology 157(Pt 10), 2745-2758. doi: $10.1099 / \mathrm{mic} .0 .049999-0$

Gürtler, V., and Stanisich, V. A. (1996). New approaches to typing and identification of bacteria using the 16S-23S rDNA spacer region. Microbiology 142(Pt 1), 3-16. doi: 10.1099/13500872-142-1-3

Herridge, D. F., Peoples, M. B., and Boddey, R. M. (2008). Global inputs of biological nitrogen fixation in agricultural systems. Plant Soil 311, 1-18. doi: 10.1007/s11104-008-9668-3

Jia, R. Z., Zhang, R. J., Wei, Q., Chen, W. F., Cho, I. K., Chen, W. X., et al. (2015). Identification and classification of rhizobia by matrix-assisted laser desorption/ionization time-of-flight mass spectrometry. J. Proteomics Bioinform 8, 98-107.

Koné, A. W., Edoukou, E. F., Tondoh, J. E., Gonnety, J. T., Angui, P. K. T., and Masse, D. (2012). Comparative study of earthworm communities, microbial biomass, and plant nutrient availability under 1-year Cajanus cajan (L.) Millsp and Lablab purpureus (L.) Sweet cultivations versus natural regrowths in a guinea savanna zone. Biol. Fertil. Soils 48, 337-347. doi: 10.1007/s00374-0110630-9
Lewin, A., Cervantes, E., Wong, C.-H., and Broughton, W. J. (1990). nodSU, two new nod genes of the broad host range Rhizobium strain NGR234 encode host-specific nodulation of the tropical tree Leucaena leucocephala. Mol. Plant Microbe Interact. 3, 317-326. doi: 10.1094/MPMI-3-317

Martens, M., Dawyndt, P., Coopman, R., Gillis, M., De Vos, P., and Willems, A. (2008). Advantages of multilocus sequence analysis for taxonomic studies: a case study using 10 housekeeping genes in the genus Ensifer (including former Sinorhizobium). Int. J. Syst. Evol. Microbiol. 58(Pt 1), 200-214. doi: 10.1099/ijs.0.65392-0

Masson-Boivin, C., Giraud, E., Perret, X., and Batut, J. (2009). Establishing nitrogen-fixing symbiosis with legumes: how many rhizobium recipes? Trends Microbiol. 17, 458-466. doi: 10.1016/j.tim.2009.07.004

Menna, P., Barcellos, F. G., and Hungria, M. (2009). Phylogeny and taxonomy of a diverse collection of Bradyrhizobium strains based on multilocus sequence analysis of the 16S rRNA gene, ITS region and $g \ln I I, \operatorname{rec} A$, atpD and dnaK genes. Int. J. Syst. Evol. Microbiol. 59, 2934-2950. doi: 10.1099/ijs.0.00 9779-0

Mousavi, S. A., Österman, J., Wahlberg, N., Nesme, X., Lavire, C., Vial, L., et al. (2014). Phylogeny of the Rhizobium-Allorhizobium-Agrobacterium clade supports the delineation of Neorhizobium gen. nov. Syst. Appl. Microbiol. 37, 208-215. doi: 10.1016/j.syapm.2013.12.007

Mula, M., and Saxena, K. (2010). Lifting the Level of Awareness on Pigeonpea A Global Perspective Arid Tropics. Patancheru :International Crops Research Institute for the Semi-Arid Tropics.

Muresu, R., Polone, E., Sulas, L., Baldan, B., Tondello, A., Delogu, G., et al. (2008). Coexistence of predominantly nonculturable rhizobia with diverse, endophytic bacterial taxa within nodules of wild legumes. FEMS Microbiol. Ecol. 63, 383-400. doi: 10.1111/j.1574-6941.2007.00424.x

Nandasena, K. G., O'Hara, G. W., Tiwari, R. P., Sezmis, E., and Howieson, J. G. (2007). In situ lateral transfer of symbiosis islands results in rapid evolution of diverse competitive strains of mesorhizobia suboptimal in symbiotic nitrogen fixation on the pasture legume Biserrula pelecinus L. Environ. Microbiol. 9, 2496-2511. doi: 10.1111/j.1462-2920.2007.01368.x

Ndabalishe, I. (1995). Agriculture Vivrière Ouest Africaine à Travers le cas de la Côte d'Ivoire. Bouaké: Institut des Savanes.

Nelson, M. S., and Sadowsky, M. J. (2015). Secretion systems and signal exchange between nitrogen-fixing rhizobia and legumes. Front. Plant Sci. 6:491. doi: 10.3389/fpls.2015.00491

Okubo, T., Tsukui, T., Maita, H., Okamoto, S., Oshima, K., Fujisawa, T., et al. (2012). Complete genome sequence of Bradyrhizobium sp. S23321: insights into symbiosis evolution in soil oligotrophs. Microbes Environ. 27, 306-315. doi: 10.1264/jsme2.ME11321

Oldroyd, G. E., Murray, J. D., Poole, P. S., and Downie, J. A. (2011). The rule of engagement in the legume-rhizobial symbiosis. Annu. Rev. Genet. 45, 119-144. doi: 10.1146/annurev-genet-110410-132549

Pandya, M., Naresh Kumar, G., and Rajkumar, S. (2013). Invasion of rhizobial infection thread by non-rhizobia for colonization of Vigna radiata root nodules. FEMS Microbiol. Lett. 348, 58-65. doi: 10.1111/1574-6968. 12245

Perret, X., Freiberg, C., Rosenthal, A., Broughton, W. J., and Fellay, R. (1999). High-resolution transcriptional analysis of the symbiotic plasmid of Rhizobium sp. NGR234. Mol. Microbiol. 32, 415-425. doi: 10.1046/j.13652958.1999.01361.x

Perret, X., Staehelin, C., and Broughton, W. J. (2000). Molecular basis of symbiotic promiscuity. Microbiol. Mol. Biol. Rev. 64, 180-201. doi: 10.1128/MMBR.64.1.180-201.2000

Pueppke, S. G., and Broughton, W. J. (1999). Rhizobium sp. strain NGR234 and R. fredii USDA257 share exceptionally broad, nested host ranges. Mol. Plant Microbe Interact. 12, 293-318.

Ramsay, J. P., Sullivan, J. T., Stuart, G. S., Lamont, I. L., and Ronson, C. W. (2006). Excision and transfer of the Mesorhizobium loti R7A symbiosis island requires an integrase IntS, a novel recombination directionality factor RdfS, and a putative relaxase RlxS. Mol. Microbiol. 62, 723-734. doi: 10.1111/j.13652958.2006.05396.x

Ramsubhag, A., Umaharan, P., and Donawa, A. (2002). Partial 16S rRNA gene sequence diversity and numerical taxonomy of slow growing pigeonpea (Cajanus cajan L Millsp) nodulating rhizobia. FEMS Microbiol. Lett. 216, 139-144. doi: 10.1111/j.1574-6968.2002.tb11427.x 
Raymond, J., Siefert, J. L., Staples, C. R., and Blankenship, R. E. (2004). The natural history of nitrogen fixation. Mol. Biol. Evol. 21, 541-554. doi: 10.1093/molbev/msh047

Rivas, R., Martens, M., de Lajudie, P., and Willems, A. (2009). Multilocus sequence analysis of the genus Bradyrhizobium. Syst. Appl. Microbiol. 32, 101-110. doi: 10.1016/j.syapm.2008.12.005

Sánchez-Juanes, F., Ferreira, L., Alonso de la Vega, P., Valverde, A., Barrios, M. L., Rivas, R., et al. (2013). MALDI-TOF mass spectrometry as a tool for differentiation of Bradyrhizobium species: application to the identification of Lupinus nodulating strains. Syst. Appl. Microbiol. 36, 565-571. doi: 10.1016/j.syapm.2013.09.003

Schleifer, K. H. (2009). Classification of Bacteria and Archaea: past, present and future. Syst. Appl. Microbiol. 32, 533-542. doi: 10.1016/j.syapm.2009.09.002

Schwarz, G. (1978). Estimating dimension of a model. Ann. Stat. 6, 461-464. doi: $10.1214 /$ aos/1176344136

Sheldrake, A. R., and Narayanan, A. (1979). Growth, development and nutrient uptake in pigeonpea (Cajanus cajan). J. Agric. Sci. (Camb.) 92, 513-526. doi: $10.1017 /$ S0021859600053752

Simões-Araújo, J. L., Leite, J., Marie Rouws, L. F., Passos, S. R., Xavier, G. R., Rumjanek, N. G., et al. (2016). Draft genome sequence of Bradyrhizobium sp. strain BR 3262, an effective microsymbiont recommended for cowpea inoculation in Brazil. Braz. J. Microbiol. 47, 783-784. doi: 10.1016/j.bjm.2016.03.001

Stanley, J., Dowling, D. N., and Broughton, W. J. (1988). Cloning of hemA from Rhizobium sp. NGR234 and symbiotic phenotype of a gene-directed mutant in diverse legume genera. Mol. Gen. Genet. 215, 32-37.

Stepkowski, T., Czaplinska, M., Miedzinska, K., and Moulin, L. (2003). The variable part of the $d n a K$ gene as an alternative marker for phylogenetic studies of rhizobia and related alpha Proteobacteria. Syst. Appl. Microbiol. 26, 483-494. doi: 10.1078/072320203770865765

Tamura, K., Stecher, G., Peterson, D., Filipski, A., and Kumar, S. (2013). MEGA6: Molecular Evolutionary Genetics Analysis version 6.0. Mol. Biol. Evol. 30, 2725-2729. doi: 10.1093/molbev/mst197

Tian, C. F., Zhou, Y. J., Zhang, Y. M., Li, Q. Q., Zhang, Y. Z., Li, D. F., et al. (2012). Comparative genomics of rhizobia nodulating soybean suggests extensive recruitment of lineage-specific genes in adaptations. Proc. Natl. Acad. Sci. U.S.A. 109, 8629-8634. doi: 10.1073/pnas.1120436109

Tokajian, S., Issa, N., Salloum, T., Ibrahim, J., and Farah, M. (2016). 16S23S rRNA Gene Intergenic Spacer Region Variability Helps Resolve Closely Related Sphingomonads. Front. Microbiol. 7:149. doi: 10.3389/fmicb.2016. 00149

Udvardi, M., and Poole, P. S. (2013). Transport and metabolism in legume-rhizobia symbioses. Annu. Rev. Plant Biol. 64, 781-805. doi: 10.1146/annurev-arplant050312-120235

van Berkum, P., Terefework, Z., Paulin, L., Suomalainen, S., Lindström, K., and Eardly, B. D. (2003). Discordant phylogenies within the rrn loci of Rhizobia. J. Bacteriol. 185, 2988-2998. doi: 10.1128/JB.185.10.2988-299 8.2003

Van der Maesen, L. J. G. (2006). "Cajanus cajan (L.) Millsp. [Internet] Fiche de PROTA4U," in PROTA (Plant Resources of Tropical Africa/Ressources Végétales de l'Afrique Tropicale), ed G. Brink (Wageningen: Pays Bas).
Varshney, R. K., Chen, W., Li, Y., Bharti, A. K., Saxena, R. K., Schlueter, J. A., et al. (2012). Draft genome sequence of pigeonpea (Cajanus cajan), an orphan legume crop of resource-poor farmers. Nat. Biotechnol. 30, 83-89. doi: $10.1038 /$ nbt. 2022

Varshney, R. K., Penmetsa, R. V., Dutta, S., Kulwal, P. L., Saxena, R. K., Datta, S., et al. (2010). Pigeonpea genomics initiative (PGI): an international effort to improve crop productivity of pigeonpea (Cajanus cajan L.). Mol. Breed. 26, 393-408. doi: 10.1007/s11032-009-9327-2

Vinuesa, P., Rojas-Jiménez, K., Contreras-Moreira, B., Mahna, S. K., Prasad, B. N., Moe, H., et al. (2008). Multilocus sequence analysis for assessment of the biogeography and evolutionary genetics of four Bradyrhizobium species that nodulate soybeans on the asiatic continent. Appl. Environ. Microbiol. 74, 6987-6996. doi: 10.1128/AEM.00875-08

Willems, A. (2006). The taxonomy of rhizobia: an overview. Plant Soil 287, 3-14. doi: 10.1007/s11104-006-9058-7

Wolde-Meskel, E., Terefework, Z., Frostegård, A., and Lindström, K. (2005). Genetic diversity and phylogeny of rhizobia isolated from agroforestry legume species in southern Ethiopia. Int. J. Syst. Evol. Microbiol. 55(Pt 4), 1439-1452. doi: 10.1099/ijs.0.63534-0

Wu, L. J., Wang, H. Q., Wang, E. T., Chen, W. X., and Tian, C. F. (2011). Genetic diversity of nodulating and non-nodulating rhizobia associated with wild soybean (Glycine soja Sieb. \& Zucc.) in different ecoregions of China. FEMS Microbiol. Ecol. 76, 439-450. doi: 10.1111/j.1574-6941.2011.01064.x

Zehr, J. P., Jenkins, B. D., Short, S. M., and Steward, G. F. (2003). Nitrogenase gene diversity and microbial community structure: a cross-system comparison. Environ. Microbiol. 5, 539-554. doi: 10.1046/j.1462-2920.2003.00451.x

Zgadzaj, R., James, E. K., Kelly, S., Kawaharada, Y., de Jonge, N., Jensen, D. B., et al. (2015). A legume genetic framework controls infection of nodules by symbiotic and endophytic bacteria. PLoS Genet. 11:e1005280. doi: 10.1371/journal.pgen.1005280

Zhang, Y. M., Tian, C. F., Sui, X. H., Chen, W. F., and Chen, W. X. (2012). Robust markers reflecting phylogeny and taxonomy of rhizobia. PLoS ONE 7:e44936. doi: 10.1371/journal.pone.0044936

Ziegler, D., Mariotti, A., Pflüger, V., Saad, M., Vogel, G., Tonolla, M., et al. (2012). In situ identification of plant-invasive bacteria with MALDI-TOF mass spectrometry. PLoS ONE 7:e37189. doi: 10.1371/journal.pone.0037189

Ziegler, D., Pothier, J. F., Ardley, J., Fossou, R. K., Pflüger, V., de Meyer, S., et al. (2015). Ribosomal protein biomarkers provide root nodule bacterial identification by MALDI-TOF MS. Appl. Microbiol. Biotechnol. 99, 5547-5562. doi: 10.1007/s00253-015-6515-3

Conflict of Interest Statement: The authors declare that the research was conducted in the absence of any commercial or financial relationships that could be construed as a potential conflict of interest.

Copyright (C) 2016 Fossou, Ziegler, Zézé, Barja and Perret. This is an open-access article distributed under the terms of the Creative Commons Attribution License (CC $B Y)$. The use, distribution or reproduction in other forums is permitted, provided the original author(s) or licensor are credited and that the original publication in this journal is cited, in accordance with accepted academic practice. No use, distribution or reproduction is permitted which does not comply with these terms. 